RESEARCH PAPER

\title{
Tobacco spending and children in low income households
}

\section{G W Thomson, N A Wilson, D O'Dea, P J Reid, P Howden-Chapman}

Tobacco Control 2002;11:372-375

See end of article for authors' affiliations ......................

Correspondence to: George Thomson, Department of Public Health, Wellington

Medical School, University of Otago, Box 7343 Wellington South, New Zealand;

gthomson@wnmeds.ac.nz

Received 8 May 2002 and revision requested

25 September 2002 Accepted 27 September 2002
Objective: To examine the role of tobacco use in creating financial hardship for New Zealand (NZ) low income households with children.

Data: The 1996 NZ census (smoking prevalence by household types), Statistics NZ (household spending surveys 1988-98), and NZ Customs (tobacco released from bond 1988-98).

Main outcome measures: Proportion of children in households with smokers and $\leqslant \$ N Z 15000$ gross income per adult. Proportion of spending on tobacco of second lowest equivalised household disposable income decile and of solo parent households.

Results: In $\leqslant$ \$NZ15 000 gross income per adult households with both children and smokers, there were over 90000 children, or $11 \%$ of the total population aged less than 15 years. Enabling second lowest income decile households with smokers to be smoker-free would on average allow an estimated $14 \%$ of the non-housing budgets of those households to be reallocated.

Conclusions: The children in low income households with smokers need to be protected from the financial hardship caused by tobacco use. This protection could take the form of more comprehensive government support for such households and stronger tobacco control programmes. A reliance on tobacco price policy alone to deter smokers is likely to have mixed outcomes - for example, increased hardship among some of these households. The challenge for tobacco control is to move from a sole focus on "doing good" towards incorporating the principle of "doing no harm".
$T$ obacco use is generally seen as a policy problem for the health sector, rather than an issue for wider social and economic policy. This report examines the potential impact of tobacco spending in low income households with children, and the ways to address child poverty through tobacco control.

Studies elsewhere have indicated that tobacco spending may impact on child poverty. Research on low income smokers and low income, lone parent smokers in Britain has suggested that tobacco price increases reduce consumption but not prevalence. ${ }^{2}$ In the USA, children in low income households with smokers had a reported poorer diet quality, compared to those in such households without smokers. ${ }^{3}$ In Bangladesh, the impact of tobacco spending on low income households may include the lives of over 100000 children per year. ${ }^{4}$

In New Zealand, there is a steep gradient of smoking and deprivation. In 1996, those living in the most socioeconomically deprived decile census areas were $260 \%$ more likely to be current smokers than those in the least deprived decile. ${ }^{5}$ This

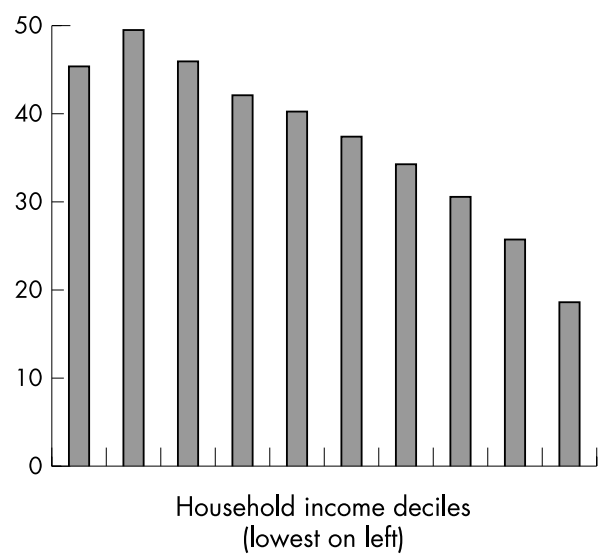

Figure 1 Proportion of children who are in households with smokers, by equivalised disposable household income deciles. Aggregated data from the 1988-98 Statistics New Zealand Household Economic Survey. gradient is also evident in other measures of socioeconomic status such as household income, education, occupational class, employment status, and household crowding. ${ }^{6}$

Children in low income households are much more likely to be affected by spending on tobacco than those in higher income households (fig 1). There has also been a belief that smokers in poorer households spend a much greater proportion of their disposable incomes on tobacco, but there are few data on this. Again, this potential disproportion has implications for children in the households. Our objectives were to find: (1) the proportion of New Zealand children affected by tobacco spending in low income households; and (2) the proportion of spending by low income households that was on tobacco.

\section{METHODS}

\section{Proportion of children affected}

The New Zealand 1996 census was the most up-to-date source of good information on the numbers of smokers in households by household income and household composition. We assumed the children (those under 15 years) in the households were dependent on the adults. The data on smokers available to us were by $\$ N Z 5000$ bands of unequivalised household gross income. "Gross income" includes government benefits, before tax.

New Zealand has no official poverty level. To estimate the proportion of children affected, a gross income level (in \$NZ) of $\leqslant \$ 15000$ per adult was adopted to define low income households. The average gross personal income in 1996 was $\$ 22800$, for males $\$ 30200$, and for females \$16 200. ${ }^{7}$ The \$15 000 level that we used was $65 \%$ of the average gross personal income.

This income level selected can be compared with the level set by the New Zealand Poverty Measurement Project (NZPMP) of $60 \%$ of the median, equivalent household disposable income. ${ }^{8}$ For 1996, this was $\$ 15300$, with the

Abbreviations: HES, Household Economic Survey; NZPMP, New Zealand Poverty Measurement Project 


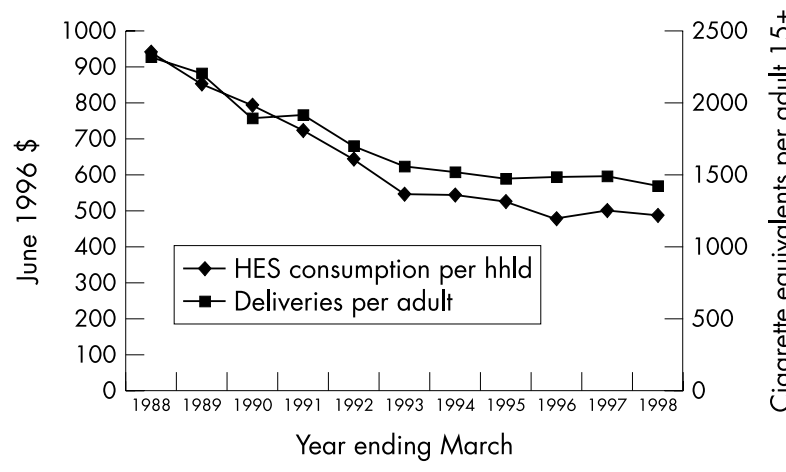

Figure 2 Comparison of trends: real tobacco consumption per household, and cigarette equivalent deliveries per adult; 1987/88 to $1997 / 98$.

median at \$25 600 and the average at \$31 800. The nonequivalised average household disposable income was $\$ 35500$ and the average household gross income was $\$ 46400 .{ }^{9}$ Thus, the level we adopted, of a gross income of $\$ 30000$ for a household with two adults, was about $65 \%$ of the average household gross income. Applying this ratio, as an approximate check, to the equivalent disposable household median of $\$ 25600$, gives a value slightly above the NZPMP poverty level. Thus $\leqslant \$ 15000$ per adult was the nearest level to the NZPMP level provided by the census data with $\$ 5000$ income bands.

\section{Proportion of household spending on tobacco}

To find the proportion of household spending on tobacco, other data from this period were used including: (1) Customs' data for tobacco released from bond (that is, for sale) in $1988-98^{10}$; and (2) Household Economic Survey (HES) data for 1996-97 on tobacco, food and housing expenditure. ${ }^{11}$ The HES data were available by equivalised disposable household income deciles.

Unpublished HES tobacco spending data for the years 1988-98 were compared to the Customs' data. The comparison found that approximately $45 \%$ of tobacco spending was reported in the HES survey. HES expenditure figures were therefore scaled up to match that in the Customs reports, assuming that the same level of underreporting occurred across all income groups and household types. The rate of underreporting over time was fairly consistent during 1988-98 (fig 2).

The total spending of households with smokers was adjusted upwards to allow for the underreporting of tobacco spending. Households with smokers are assumed to have non-tobacco spending that was similar to that of households without smokers. The average amount reported by the HES as spent on tobacco (for example, \$10.50), by household type (for example, second income decile), was divided by the percentage of households reporting tobacco spending (for example, $30 \%)$, to obtain the estimated spending on tobacco per household with smokers (for example, \$35).

Our analysis used the tobacco spending in the households with solo adults and children, and the spending in the second lowest decile of household income, as the best indicators of the greatest impact from tobacco on low income households. Spending in the lowest income decile households was reported by the 1996-97 HES survey as over \$4000/year more than for the second lowest (\$23 300 compared to $\$ 19000 /$ year). The reason for this appears to be that self employed people, reporting in low or non-income years, skew the lowest income decile data. The available data did not allow the exclusion of the self employed.

\section{RESULTS}

Population of children in households with smokers

Of the 145000 New Zealand households with both smokers and children, about 34\% (over 50 000) in 1996 reported an annual gross income of $\leqslant \$ 15000$ per adult. Over 90000 children lived in these households, which was $11 \%$ of the total population of those aged less than 15 years. Furthermore, there were over 29000 of these low income households with two or more adults who smoked.

Of all households with children and a solo adult who smoked, 58\% (15 000) reported an annual household gross income of $\leqslant \$ 15000$. This group of households with sole parents who smoked, were $25 \%$ of all households with a solo adult and children. In this group $90 \%$ of the adults were women and $35 \%$ of the adults were Maori women.

\section{Tobacco as a proportion of household spending}

For the second lowest income decile of households with smokers (with and without children) the estimated average tobacco spending was about $\$ 35 /$ week or $\$ 1800 /$ year. This was $9.1 \%$ of household spending, adjusted for the underreporting of tobacco spending. The expenditure was $64 \%$ of reported food spending or $27 \%$ of reported housing spending. In 1996$97, \$ 1800$ per year was the cost of buying a packet of 20 low price cigarettes per day. However, if tobacco spending is compared to total spending, less housing costs, then the greater proportion of tobacco spending by the second lowest decile households is clearer.

As $70 \%$ of the cost of tobacco went to the government in taxes, ${ }^{12}$ these households with smokers contributed an average of about $\$ 1250$ per household to government, compared to non-smoking households. The average net income transfer through government benefits, less income tax, to households for this decile was about $\$ 12000$ in $1996 .{ }^{13}$ Thus, for households in this income decile with smokers, on average over $10 \%$ of this net income transfer through benefits would be returned to the government as tobacco taxes.

For households with sole adults and children (in all income brackets) that reported spending on tobacco, an average of around $6 \%$ of spending was on tobacco ( $\$ 28 /$ week or $\$ 1500 /$ year). This amount was equal to about $40 \%$ of reported food spending and 18\% of reported housing spending. For households with sole adults who smoke and children, and a gross income of $\leqslant \$ 15000 /$ year (over $50 \%$ of such households), the same rate of tobacco spending (\$28/week) would be $10 \%$ or more of total spending (table 1 ).

\section{DISCUSSION}

\section{Principal findings}

The estimated expenditure by some low income households, of almost $14 \%$ of non-housing household spending on tobacco, has the potential to affect the well being of children in households with smokers. This impact is over and above the higher likelihood of the children in these households becoming smokers, ${ }^{514}{ }^{15}$ and the direct effects on their health through inhaling secondhand smoke. ${ }^{16}{ }^{17}$ The greater than average proportion of disposable income spent on tobacco by some low income households indicates an even greater inequity of outcomes for children in these households.

In households with heavy or multiple smokers, the proportion of expenditure on tobacco could be much higher. For the $11 \%$ of all New Zealand children, who were in households with smokers and where the income was less than $\$ 15000$ per adult, the tobacco spending appears likely to affect the level of food quality, food security, housing quality, educational experiences, and health care available to them. These factors are likely to affect their later health and opportunities. ${ }^{18-20}$

Because Maori and Pacific children are more likely to be in both a socioeconomically deprived household and a household with smokers, ${ }^{5}$ they are at greater risk from the financial impacts of smoking. During 1988-98, Maori children were almost twice as likely to be in a household with smokers, compared to non-Maori children. ${ }^{21}$ These financial and health factors caused by smoking contribute to the existing socioeconomic inequalities between ethnic groups. ${ }^{22}$ 
Table 1 Average weekly expenditure by household type, year to March 1997 (122\% added to reported tobacco spending). Deciles are for equivalised disposable household income

\begin{tabular}{|c|c|c|c|c|}
\hline & $\begin{array}{l}1 \text { adult, } 1 \text { or more } \\
\text { children (\$NZ) }\end{array}$ & $\begin{array}{l}\text { Lowest income } \\
\text { decile (\$NZ) }\end{array}$ & $\begin{array}{l}\text { Second lowest income } \\
\text { decile (\$NZ) }\end{array}$ & $\begin{array}{l}\text { All households } \\
\text { (\$NZ) }\end{array}$ \\
\hline \multicolumn{5}{|l|}{ Spending area } \\
\hline Tobacco* & $28(6.1 \% \dagger)$ & $34(7.3 \% \dagger)$ & $35(9.1 \% \dagger)$ & $56(8.1 \% \dagger)$ \\
\hline Housing & 160 & 130 & 130 & 134 \\
\hline Food & 70 & 70 & 55 & 109 \\
\hline Total reported spending & 446 & 448 & 366 & 663 \\
\hline Total spending adjusted for underreporting & 461 & 467 & 385 & 694 \\
\hline Adjusted total spending less housing & $301(9.3 \% \ddagger)$ & $337(10.1 \% \ddagger)$ & $255(13.7 \% \ddagger)$ & $560(10 \% \ddagger)$ \\
\hline
\end{tabular}

*The tobacco spending is the average for those households which report that spending, not the average for all households of that type.

†Tobacco as a percentage of total spending, adjusted for the underreporting of tobacco spending. Households with smokers are assumed to have non-tobacco spending that was similar to households without smokers.

$\ddagger$ Percentage of which is on tobacco.

In New Zealand, the tobacco industry has been responsible for promoting smoking, ${ }^{23}$ and the government has been responsible for providing inadequate tobacco control policies. ${ }^{24}{ }^{25}$ A greater emphasis by government on controlling all aspects of the industry, and helping nicotine dependent smokers to quit, appears to be a necessity in order to reduce the financial and other impacts of smoking on children.

\section{Limitations of this study}

The proportion of New Zealand children affected by tobacco spending in low income households would be better identified by the use of equivalised household income census data. There are significant limitations with the quality of data reported in the HES. While an adjustment was made for the underreporting of household tobacco expenditure (which has not been reported previously) this did not address possible variations in underreporting by household type. Also, it was likely that some households erroneously reported no tobacco spending. No adjustment could be made for this.

An underestimate of the proportion of the total spending of households with smokers that was on tobacco may have resulted from two causes. They were: (1) the upward adjustment of the total spending of households with smokers, to allow for the underreporting of tobacco spending; and (2) the assumption that households with smokers had nontobacco spending that was similar to that of households without smokers.

Our analysis was not able to identify the degree to which tobacco displaces expenditure on those areas most critical to child health (for example, food quality and housing quality). More detailed analysis of HES data (including analysis by ethnicity) is necessary if a clearer understanding of the role of tobacco use in financial hardship is to be obtained. Nevertheless, this analysis is the first to give some quantification as to the way that tobacco use may impact on the financial hardship of New Zealand low income households with children.

\section{Implications for policymakers}

Tobacco control activities have generally been premised on reducing the direct health effects of tobacco use. These efforts have resulted in a tension between actions that are anti-tobacco and a range of consequences (such as financial impacts) that are punitive and anti-smoker. The challenge for tobacco control is to move from a sole focus on "doing good" towards incorporating the principle of "doing no harm".

Besides the need to reduce tobacco use, policy makers need to also consider options to minimise the potential financial hardship and inequity associated with tobacco use. The options include the following.

\section{(1) Improving the social wage for all low income} households

This option could be achieved by various government actions (for example, increasing benefit payments, employment opportunities, low cost housing and minimum wage levels, and by targeted reductions of income tax rates). For developed countries, those in relatively socioeconomically deprived groups appear to be more likely to start smoking and less likely to be able to quit. ${ }^{122627}$ Therefore reducing social disparities would appear to have positive effects for tobacco control. If this option is accompanied by stronger tobacco control action, then the short term effect on tobacco consumption of increased real income could be minimised.

\section{(2) Developing a stronger and more comprehensive tobacco control programme}

There are many tobacco control interventions of proven effectiveness, including smokefree environments, ${ }^{28} 29$ mass media campaigns, ${ }^{30}{ }^{31}$ and smoking cessation activities (for example, involving telephone quitlines, ${ }^{32}$ provision of nicotine replacement therapy, ${ }^{33}$ and quit and win contests $\left.{ }^{34}\right)$. Interventions that take into account the apparent likelihood of higher nicotine dependence in those with greater socioeconomic deprivation ${ }^{27}$ would be particularly helpful in reducing the impact of smoking on child poverty.

While New Zealand continues to slowly develop its tobacco control activities, major components such as mass media campaigns and smoking cessation programmes remain poorly funded in relation to the tax revenue gained. Tobacco control services for Maori are also minuscule relative the tobacco taxes they pay. New Zealand tobacco control spending in 2001-2002 was about \$28 million/year, or \$56 per smoker. This was less than 3\% of the at-least $\$ 950$ million government revenue from tobacco. ${ }^{12}$

\section{(3) Using price as the primary intervention}

This usually occurs when tobacco taxes are raised, without an equal investment in tobacco control. However, reducing tobacco taxes could arguably reduce child poverty, and this option is considered first.

Reducing the price of tobacco would slow the decline in tobacco consumption and could even increase consumption, leading to adverse tobacco related health consequences for low income households and the children in them. There could also be higher rates of smoking uptake by youth in the long term..$^{356}$ These are important disadvantages to set against any possible reduction in financial hardship of low income households with children.

Where increased tobacco prices prompted quitting, reduced consumption, and reduced uptake of smoking by youth, there would be lower financial hardship and improved health in at least some of the affected households. However, where smokers did not quit or cut down sufficiently after a tobacco price rise, average household spending on tobacco would increase. For a $10 \%$ tobacco price rise, where smokers did not subsequently quit, the 1988-98 New Zealand data indicate that for the year 2000, a household with a solo smoking adult 


\section{What this paper adds}

There have been a limited number of published studies that have measured the effect of tobacco spending on low income households with children. The studies have indicated the potential for a poorer diet for children in these households.

This paper indicates that over 10\% of New Zealand children in 1996 were in low income households affected by tobacco spending. Where low income households contained smokers, potentially $10 \%$ of their spending was on tobacco. More comprehensive government support and stronger tobacco control are suggested as a means to decrease the impact of tobacco on child poverty.

with children would on average have spent \$70-100 more per year on tobacco. ${ }^{21}$ This is for an estimated decrease of consumption of $5-8 \%$ for a $10 \%$ price increase (a price elasticity of demand of $0.5-0.8$ ).

Increasing prices involves a trade-off between imposing increased financial hardship on some households, and providing both health and financial benefits for others. While a price elasticity of 1.0 or over would on average produce no extra spending after tobacco price rises, this price response is rarely found in adult populations in developed countries. ${ }^{37}$ Even if this average response was found in low income deciles, there would still be a proportion of households in these deciles where price rises would produce adverse financial impacts. There are also ethical concerns when a government uses tax revenue from a highly dangerous and addictive substance for general purposes, in the context of inadequate support for smoking cessation and prevention.

\section{Policy recommendation}

Of the above options, the best from a child health and welfare promotion perspective are options 1 and 2, particularly if all tobacco tax revenue is used for tobacco control. We suggest that raising tobacco taxes, without an equal investment in tobacco control, can adversely affect children in low income households. Properly resourced tobacco control is therefore a potentially important way to address child poverty and health, as well as the ethnic disparities in these outcomes.

\section{ACKNOWLEDGEMENTS}

Funding was received from the New Zealand Heart Foundation and the New Zealand Cancer Society, and the Smokefree Coalition and Aparangi Tautoko Auahi Kore helped facilitate the project. Statistics New Zealand provided advice along with their data. These groups are of course not responsible for the opinions expressed. The perceptive comments by the anonymous reviewers were much appreciated.

\section{Authors' affiliations}

G W Thomson, D O'Dea, P J Reid, P Howden-Chapman,

Department of Public Health, Wellington School of Medicine and Health Sciences, University of Otago, Wellington, New Zealand

N A Wilson, Wellington, New Zealand

\section{REFERENCES}

1 Marsh A, McKay S. Poor smokers. London: Policy Studies Institute, 1994.

2 Dorsett R, Marsh A. The health trap: poverty, smoking and lone parenthood. London: Policy Studies Institute, 1998.

3 Johnson R K, Wang M. The association between parental smoking and the diet quality of low-income children. Pediatrics 1996;97:312-17

4 Efroymson D, Ahmed S, Townsend J, et al. Hungry for tobacco: an analysis of the economic impact of tobacco consumption on the poor in Bangladesh. Tobacco Control 2001;10:212-7.

5 Tobias M, Cheng J. Inhaling inequality: tobacco's contribution to health inequality in New Zealand. (Public Health Intelligence Occasional
Bulletin No. 7). Wellington: Ministry of Health, 2001:9. URL: http://www.moh.govt.nz/moh.nsf/wpg_Index/Publications-Index

6 Howden-Chapman P, ed. Social inequalities and health: report to the Ministry of Health. Wellington: Department of Public Health, Wellington School of Medicine, University of Otago, 2000:74, 92, 107, 110, 143

7 Statistics New Zealand. New Zealand now: incomes. Wellington: Statistics New Zealand, 1999:45-6.

8 Stephens R, Frater P, Waldegrave C. Below the line: an analysis of income poverty in New Zealand, 1984-1998. The Family Centre, Lower Hutt, 2000.

9 Statistics New Zealand. New Zealand now: incomes. Wellington: Statistics New Zealand, 1999:67 and table 4.5.

10 Ministry of Health. Tobacco facts May 2001. Wellington: Ministry of Health, 2001. URL: http://www.ndp.govt.nz/ (tobacco, resources)

11 Statistics New Zealand. Household Economic Survey standard tables 1996/7. Wellington: Statistics New Zealand, 1997.

12 Tax Review 2001. Issues Paper. Wellington: New Zealand Government 2001:50

13 Statistics New Zealand. New Zealand now: incomes. Wellington: Statistics New Zealand, 1999:65

14 Ministry of Health. Taking the pulse: The 1996/97 New Zealand Health Survey. Wellington: Ministry of Health, 1999:31.

15 Turrell G, Battistutta D, McGuffog I. Social determinants of smoking among parents with infants. Aust N Z J Public Health 2002;26:30-7

16 Lam TH, Leung GM, Ho LM. The effects of environmental tobacco smoke on health services utilization in the first eighteen months of life. Pediatrics 2001; 107:E91.

17 Li JS, Peat JK, Xuan W, et al. Meta-analysis on the association between environmental tobacco smoke (ETS) exposure and the prevalence of ower respiratory tract infection in early childhood. Pediatr Pulmonol 1999;27:5-15.

18 Blackwell DL, Hayward MD, Crimmins EM. Does childhood health affect chronic morbidity in later life? Soc Sci Med 2001;52:1269-84.

19 Nelson M. Childhood nutrition and poverty. Proc Nutr Soc 2000;59:307-15

20 Morley R. The influence of early diet on later development. J Biosoc Sci 1996;28:481-7.

21 Thomson G, O'Dea D, Wilson N, et al. The effects of tobacco tax increases on Maori and low-income families. Wellington: Department of Public Health, Wellington School of Medicine, University of Otago, 2000: 14, 17. URL: http://www.wnmeds.ac.nz/academic/dph/ Publicationsreports/FinancialEffects.doc

22 O'Dea D, Howden-Chapman P. Income and income inequality and health. In: Howden-Chapman P, Tobias M, eds. Social inequalities and health: New Zealand 1999. Wellington: Ministry of Health, 2000:79.

23 Thomson G, Wilson N. The tobacco industry in New Zealand: a case study of the behaviour of multinational companies. Wellington, Department of Public Health, Wellington School of Medicine, University of Otago, 2002. URL: http://www.wnmeds.ac.nz/academic/dph/ Publicationsreports/TobaccoMonograph.pdf.

24 Thomson G, Wilson N. Tobacco control policy. In: Davis P, Ashton T, eds. Health and public policy in New Zealand. Auckland: Oxford University Press, 2001

25 Thomson G, Wilson N. Lost in the smoke: tobacco control in New Zealand during the 1990s. NZ Med J 2000;113:122-3.

26 Crampton P, Salmond C, Woodward A, et al. Socioeconomic deprivation and ethnicity are both important for anti-tobacco health promotion. Health Educ Behav 2000;27:317-27.

27 Jarvis $M$, Wardle J. Social patterning of individual health behaviours: the case of cigarette smoking. In: Marmot M, Wilkinson R, eds. Socia determinants of health. Oxford: Oxford University Press, 1999.

28 Serra C, Cabezas C, Bonfill X, et al. Interventions for preventing tobacco smoking in public places. Cochrane Tobacco Addiction Group, Cochrane Database of Systematic Reviews. Issue 3, 2001

29 Chapman S, Borland R, Brownson R, et al. The impact of workplace smoking bans on declining cigarette consumption in Australia and the USA. Am J Public Health 1999:89:1018-23.

30 Flay BR. Mass media and smoking cessation: a critical review. Am J Public Health 1987;77:153-60.

31 Sowden AJ, Arblaster L. Mass media interventions for preventing smoking in young people. Cochrane Tobacco Addiction Group, Cochrane Database of Systematic Reviews. Issue 3, 2001

32 Stead LF, Lancaster T. Telephone counselling for smoking cessation. Cochrane Tobacco Addiction Group, Cochrane Database of Systematic Reviews. Issue 3, 2001.

33 Stead LF, Lancaster T, Silagy CA. Updating a systematic review - what difference did it make? Case study of nicotine replacement therapy. BMC Med Res Methodol 2001;1:10.

34 Bains N, Pickett W, Hoey J. The use and impact of incentives in population-based smoking cessation programs: a review. Am J Health Promot 1998; 12:307-20.

35 Jha $\mathbf{P}$, Chaloupka FJ. The economics of global tobacco control. BM 2000;321:358-61

36 Hamilton V H, Levinton C, St Pierre Y, et al. The effect of tobacco tax cuts on cigarette smoking in Canada. Can Med Assoc J 1997; 156:187-91.

37 Chaloupka FJ, Hu T-W, Warner KE, et al. The taxation of tobacco products. In: Jha P, Chaloupka FJ, eds. Tobacco control in developing countries. Oxford: Oxford University Press, 2000:237-72. 